\title{
A study to assess the reliability and construct validity of the Abbreviated Self- leadership Questionnaire: a South African study
}

Bright Mahembe, Amos Engelbrecht and Zani Wakelin

\begin{abstract}
Self-leadership has been recognised as a fundamental competency for effective learning and job performance. The primary goal of this study was to validate the Abbreviated Selfleadership Questionnaire on a South African sample. Numerous questionnaires have been developed to measure self-leadership, with the Revised Self-leadership Questionnaire being the most widely used questionnaire. However, the Revised Self-leadership Questionnaire has been deemed too long; hence, the authors abbreviated the measure. Therefore, there is a need to assess the reliability and construct validity of the abbreviated Self-leadership Questionnaire on a South African sample. A non-probability sample consisting of 400 students drawn from a university in the Western Cape was used. The reliability of the Abbreviated Self-leadership Questionnaire was evaluated using SPSS, while construct validity was assessed via confirmatory factory analyses in the LISREL program. Moderate levels of reliability were found for the subscales of the Abbreviated Self-leadership Questionnaire. Reasonable model fit with the data was found for the first-order measurement model. The study contributes to the requirements of the Amended Employment Equity Act of South Africa (Republic of South Africa, 1998) which promotes the use of reliable and valid instruments in South Africa by confirming the psychometric properties of the Abbreviated Self-leadership Questionnaire.
\end{abstract}

The 21st-century South African organisation is faced with an arduous challenge of meeting the employment equity targets which is largely due to the aftermath of the legacy of apartheid which perpetuated unequal subgroup exposure to education or training particularly for Blacks and women. According to the Commission for Employment Equity (2012), very little progress has been made in transforming the upper echelons of organisations in the private sector. White men still occupy the majority of the top management positions in the private sector (65.4\%), Black men with $18.5 \%$, Indian male population with $4.5 \%$, Coloured male population with $3 \%$, and foreigner male population accounting for about $2.1 \%$. One of the reasons behind the skewed distributions is the dearth of suitably qualified employees from the designated groups (Esterhuyse, 2008). Efforts to identify and develop the learning competencies that distinguish between successful and unsuccessful learners are being undertaken (Burger, 2012; De Goede \& Theron, 2010; Mahembe, 2014; Van Heerden \& Theron, 2014) to help redress the situation. Various models have been developed to identify the competencies and competency potential variables that are characteristic of successful learning/job 
performance with a view to develop these competencies in the larger segment of the population that was previously disadvantaged. Organisations are getting frustrated by failures to meet the equity targets as a result of a restricted pool from which to draw potential employees. To date, most of the models that have attempted to identify and explain competencies that distinguish between successful and unsuccessful learners and job performers have identified self-leadership as one of the important learning and job performance characteristics (Burger, 2012; Cunnington, 1985; Mahembe, 2014; Tichy \& Sherman, 1993).

Self-leadership is anchored on individually initiated thinking processes that are intrinsically motivated and crucial for organisational and learning performance (Mahembe, 2014; Manz, 1986; Manz \& Neck, 2004; Van Zyl, 2008). Self-leading individuals derive their rewards from feelings of intrinsic satisfaction, not external motivation. Previous studies document a myriad of benefits that are derived from self-leading individuals. Some of these benefits include improved performance (Neck \& Manz, 2010; Stewart, Courtright \& Manz, 2011), enhanced confidence (Stajkovic \& Luthans, 1998), goal achievement (Neck \& Houghton, 2006), and heightened individual creativity potential (Curral \& MarquesQuinteiro, 2009; DiLiello \& Houghton, 2006). In the learning context, self-leading individuals adopt a learning orientation (Curral \& Marques-Quinteiro, 2009), combined with proactive self-improvement efforts (Norris, 2008; Ryan \& Deci, 2000), a high motivation to learn, and is positively linked to the self-efficacy personality aspect (Barling \& Beattie, 1983; Mahembe, 2014; Ross, 2014). Within an applied social context, self-leadership has also been linked to increased functional team dynamical aspects such as team satisfaction, performance, effectiveness (Gil, Rico, Alcover, \& Barrasa, 2005), trust, commitment, and shared leadership between team members (Bligh, Pearce, \& Kohles, 2006).

Despite self-leadership being viewed as an essential pre-requisite for effective individualinitiated functioning, its success in predicting individual performance has been marred by the lack of a universal and psychometrically sound research instrument to measure its existence (Markham \& Markham, 1998). It is therefore important to test the psychometric properties of the Abbreviated Self-leadership Questionnaire (ASLQ) on a South African sample to ensure compliance with the Amended Employment Equity Act of South Africa (Republic of South Africa, 1998, 2014) which promotes the use of reliable and valid instruments in South Africa. This study was designed to test the reliability and construct validity (including discriminant validity) of the ASLQ in determining whether the original factor structure developed in the United States by Houghton, Dawley, and DiLiello (2012) can be confirmed on a South African sample. The ASLQ offers a shorter and easy-to-use questionnaire compared to the original Revised Self-leadership Questionnaire (RSLQ) developed by Houghton and Neck (2002).

\section{Self-leadership theory}

Self-leadership theory has its roots in self-control theory (Cautela, 1969; Thoresen \& Mahoney, 1974), the social learning theory (Bandura, 1977), self-regulation theory (Carver \& Scheier, 1981; Kanfer, 1970), social cognitive theory (Bandura, 1986), intrinsic motivation 
theory (e.g., Deci \& Ryan, 1985), and self-management (Manz, 1991). Self-leadership works via three primary self-leadership strategies, namely, behaviour-focused, natural reward, and constructive thought pattern strategies (Manz, 1986; Manz \& Neck, 2004).

Behaviour-focused strategies are designed to encourage positive, desirable behaviours that lead to successful outcomes (Neck \& Houghton, 2006). These include using self-goal setting, self-observation, self-cueing (or external signalling), self-reward, and selfpunishment (or constructive self-feedback; Manz \& Neck, 2004).

Natural reward strategies are designed to enhance the subjective experience of competence and self-determination by concentrating on enjoyable task features (Alves et al., 2006; Manz \& Neck, 2004).

Constructive thought strategies entail the formation of constructive thought patterns and reduction of dysfunctional thoughts (Alves et al., 2006; Manz \& Neck, 2004). These encompass visualising performance, use of positive self-talk, and aligning individual beliefs and assumptions with the desired behaviour (Neck \& Manz, 1996; Neck, Stewart \& Manz, 1995).

\section{Self-leadership measurement}

To date, a few research instruments have been developed and are still being validated for use in different geographical settings. Three notable preliminary self-leadership research instruments were developed by Manz (1993a, 1993b, 1993c), Cox (1993), and Anderson and Prussia (1997). The RSLQ appears to be one of the most widely used instruments for measuring self-leadership although it is still being tested for reliability and construct validity in various settings (Houghton \& Neck, 2002). The RSLQ consists of 35 items measuring nine first-order dimensions representing three self-leadership second-order dimensions, namely, behaviour-focused, natural reward, and constructive thought dimensions. The behaviour-focused dimension is made up of five subscales: self-goal setting, self-reward, selfpunishment, self-observation, and self-cueing. The natural reward dimension consists of one subscale, that is, when an individual engages in an activity for its own intrinsic value and is motivated by the task itself, while the constructive thought dimension has three sub-scales: visualising successful performance, self-talk, and evaluating beliefs and assumptions.

The RSLQ has been consistently reported to be reliable and exhibit construct validity in various settings that include China (Ho \& Nesbit, 2009; Neubert \& Wu, 2006), Portugal (Curral \& Marques-Quinteiro, 2009), Turkey (Dogan \& Sahin, 2008), Germany (Andressen \& Konradt, 2007), and South Africa (Mahembe, Engelbrecht \& De Kock, 2013; Nel \& Van Zyl, 2015). The main criticism levelled against the RSLQ relates to the length of the scale which is made up of 35 items. Given the fact that self-leadership strategies are rooted in theories of self-regulation, self-control, and self-management, Houghton et al. (2012) decided to resolve this problem by reducing the 35-item RSLQ to nine items measuring three factors (behaviour awareness and volition, task motivation, and constructive cognition). It is therefore important to correspondingly assess the reliability and construct validity of the 
ASLQ on a South African sample since the instrument has been modified and tested using samples from Europe. Although a study has been conducted in South Africa by Nel and Van $\mathrm{Zyl}$ (2015) to test the psychometric properties of the ASLQ, construct validity cannot be established in a single study and requires an accumulation of evidence using different samples. Unlike the Nel and Van Zyl (2015) study which used working participants, mainly women, who constituted $70 \%$ of the total sample, this study used a less skewed (in terms of gender) sample made up of students. The objective of this study, therefore, is to test the reliability and construct validity (including the discriminant validity) of the ASLQ on a student sample.

\section{Method \\ Participants}

The investigation was carried out at a university situated in the Western Cape Province of South Africa where the participants were undergraduate students drawn using a nonprobability sampling strategy. A total of 400 students took part in the study. The sample consisted of 229 female (57.3\%) and 171 male (42.7\%) participants. The majority (78.3\%) fell in the age category 20 years and below. The ethnic distribution in the sample was White people (28.5\%), Mixed race people (34.5\%), Indian (6.3\%), and Black people (27\%). The majority (95\%) of respondents had a matric qualification as the highest level of education, while $4.1 \%$ had a diploma.

\section{Instrument}

Selfleadership was measured using the ASLQ (Houghton et al., 2012). The ASLQ is a selfreport measure that comprises nine items measuring three factors, namely, behaviour awareness and volition, task motivation, and constructive cognition. The 9-item statements were scored by means of a 5-point Likert scale ranging from 1 (strongly disagree) to 5 (strongly agree). Example items are as follows: I establish specific goals for my own performance (behaviour awareness and volition); I visualise myself successfully performing a task before I do it (task motivation and constructive cognition); and I think about my own beliefs and assumptions whenever I encounter a difficult situation (constructive cognition).

\section{Procedure}

Access to the sample was achieved through personal delivery of the questionnaires to the various academic departments at the selected university. The participants received the ASLQ which included a covering letter and a biographical section. The covering letter introduced the reason for the study and instructions on completing the questionnaires, as well as information concerning the participants' ethical rights. In terms of ethics, permission for the study was obtained from the institution's research ethics committee. Informed consent was provided by the participants before completion of the questionnaires. Anonymity of the information and confidentiality of the data obtained were maintained throughout the research investigation. 


\section{Ethical considerations}

Before conducting the study, ethical clearance was sought from the Stellenbosch University Ethics Committee. Participants were informed of the purpose of the study as well as their rights to anonymity, voluntary participation, confidentiality, and informed consent through a cover letter provided as part of the questionnaire.

\section{Data analysis}

Item and dimensional (exploratory factor analysis [EFA]) analyses were performed via SPSS to determine the reliability and dimensionality of the instrument. The data were analysed through structural equation modelling (SEM) to ascertain the construct validity of the ASLQ.

SEM explains the relationships in the measurement and structural model using covariance analysis (Diamantopoulos \& Siguaw, 2000). The measurement model describes how each latent variable is operationalised by the corresponding manifest indicators, while the structural model describes the relationships between the latent variables themselves (Diamantopoulos \& Siguaw, 2000).

LISREL 8.80 (Jöreskog \& Sörbom, 2006) was used to perform a first-order and competing single-factor confirmatory factor analysis (CFA) on the ASLQ to determine the fit of the model. Robust maximum likelihood (RML) estimation was used to estimate the parameters set free in the model because of the lack of multivariate normality in the data (Jöreskog \& Sörbom, 1996).

Evaluation of fit of the first-order and single-factor models was based on the root mean square error of approximation (RMSEA), root mean squared residual (RMR), goodnessof-fit index (GFI), adjusted GFI, normed fit index (NFI), non-normed Fit Index (NNFI), comparative fit index (CFI), incremental fit index (IFI), and relative fit index (RFI).

The RMSEA is a measure of closeness of fit and is generally regarded as one of the most informative fit indices. When assessing the RMSEA, values less than .05 are indicative of good fit, those between .05 and under .08 indicate reasonable fit, values between .08 and .10 indicate mediocre fit, and those above 10 indicate poor fit (Diamantopoulos \& Siguaw, 2000).

The RMR is a summary measure of fitted residuals and presents the average value of the difference between the sample covariance (variance) and a fitted (model-implied) covariance (variance). In the assessment of the RMR, values below .05 are indicative of acceptable fit (Diamantopoulos \& Siguaw, 2000).

The GFI shows how closely the model comes to perfectly reproducing the observed covariance matrix. The values of the GFI should range between 0 and 1 , and values greater than .90 are usually interpreted as reflecting acceptable fit (Diamantopoulos \& Siguaw, 2000). 
The next set of fit indices to be discussed is the relative fit indices that serve as an indication to what extent the model reveals an even better fit when compared to a baseline model, usually the independence model. The NFI and the NNFI should range between 0 and 1 , with values closer to 1 representing good fit (Diamantopoulos \& Siguaw, 2000).

\section{Results}

\section{Missing values}

The concern regarding missing values was addressed through the multiple imputation method (Jöreskog \& Sörbom, 2006). Through this technique, missing values are substituted by values derived from averages obtained via simulation (Jöreskog \& Sörbom, 2006; Rubin, 1987). The use of this technique resulted in an effective sample size of 400 cases.

\section{Evaluating the measurement models}

The content and structure of the constructs were investigated by means of item analysis, as well as CFA, through LISREL 8.80 (Du Toit \& Du Toit, 2001; Jöreskog \& Sörbom, 2006) to evaluate the construct validity of the measurement models. This study intended to determine whether the original factor structure developed in the United States by Houghton et al. (2012) can be confirmed on a South African sample.

\section{Multivariate normality}

The maximum likelihood method of estimation was used to ensure normality. However, the robust maximum likelihood (RML) estimation method was automatically performed to normalise the data in the event of the failure of the maximum likelihood method.

Table I. Reliability and exploratory factor analysis output for the ASLQ dimensions.

\begin{tabular}{lllll}
\hline Scale & $\begin{array}{l}\text { Number } \\
\text { of items }\end{array}$ & $\begin{array}{l}\text { Cronbach's } \\
\text { alpha }\end{array}$ & $\begin{array}{l}\text { Factor } \\
\text { loadings }\end{array}$ & $\begin{array}{l}\text { \% Variance } \\
\text { explained }\end{array}$ \\
\hline I. Behaviour awareness and volition & 3 & .66 & $.27-.80$ & 54.4 \\
2. Task motivation & 3 & .68 & $.33-.89$ & 62.5 \\
3. Constructive cognition & 3 & .54 & $.49-.80$ & 60.4 \\
Total scale & 9 & .77 & & \\
\hline
\end{tabular}

ASLQ: Abbreviated Self-leadership Questionnaire. 
Table 2. Inter-correlations between latent ASLQ dimensions, AVE, and shared variance estimates $(N=400)$.

\begin{tabular}{llllll}
\hline Subscales & $M$ & $S D$ & 1 & 2 & 3 \\
\hline I. Behaviour awareness and volition & 11.99 & 3.81 & .43 & .18 & .12 \\
2. Task motivation & 10.76 & 6.24 & $.42^{\text {*k }}$ & .53 & .21 \\
3. Constructive cognition & 11.29 & 4.49 & $.34^{\text {*k }}$ & $.46^{\text {** }}$ & .37 \\
\hline
\end{tabular}

ASLQ: Abbreviated Self-leadership Questionnaire; AVE: average variance extracted; SD: standard deviation. $N=400$; correlations are below the diagonal, squared correlations are above the diagonal, and AVE estimates are presented on the diagonal (in bold).

**op $<.05$ (two-tailed).

The normalised dataset was used in the subsequent analysis.

\section{Item analysis}

Item and dimensional analyses were performed on the items of the ASLQ using the SPSS Reliability procedure (IBM Corporation, 2015; see Table 1). The internal consistency coefficients of all the subscales of the ASLQ missed the acceptable cut-off level $(\alpha>.70$; Nunnally \& Bernstein, 1994; see Table 1) with the exception of the single-factor model in which the ASLQ was treated as a uni-dimensional scale. The internal consistency coefficients could not be improved upon due to the limited number of items in each of the subscales. The subscales of the ASLQ were found to be uni-dimensional and the variance explained by each of the factors is generally above 50\% (see Table 1). The correlations among the three latent ASLQ dimensions are given in Table 2. The correlations are seen to be within reasonable limits, as high values (above .90) may indicate multi-collinearity (Tabachnick \& Fidell, 2001).

\section{Goodness-of-fit of the first-order and single-factor measurement models}

In terms of the goodness of fit indices (GFI) reported in Table 3, the RMSEA value of .0713 suggested that the first-order measurement model shows reasonable model fit (Diamantopoulos \& Siguaw, 2000). The RMR value of .0814 and the SRMR value of .0756 indicate that both indices missed the acceptable model fit $(<.05)$ level. The GFI and AGFI values for the first-order model are above the .90 level indicative of good fit. In comparison, the fit indices for the single-factor model indicate poor model fit. The RMSEA value of .14 and SRMR value of .075 are indicative of poor fit, and this picture is confirmed by the GFI, RFI, and IFI values which are generally below the .90 cut-off level. 
Table 3. Goodness-of-fit indices obtained for the ASLQ first-order and single-factor measurement models.

\begin{tabular}{llllllllll}
\hline Model & pclose fit & RMSEA & SRMR & GFI & NFI & NNFI & CFI & IFI & RFI \\
\hline First-order CFA & .03 & .071 & .076 & .96 & .95 & .94 & .96 & .96 & .96 \\
Single-factor model & .0 & .14 & .075 & .87 & .83 & .80 & .85 & .85 & .78 \\
\hline
\end{tabular}

ASLQ: Abbreviated Self-leadership Questionnaire; pclose fit: $p$-value for test of close fit $\left(H_{0}\right.$ : RMSEA <.05); RMSEA: root mean square error of approximation; SRMR: standardised root mean residual; GFI: goodness-of-fit index; NFI: normed fit index; NNFI: non-normed fit index; CFI: comparative fit index; IFI: incremental fit index; RFI: relative fit index; CFA: confirmatory factor analysis.

Table 4. Completely standardised solution LAMBDA-X for the ASLQ model.

\begin{tabular}{llll}
\hline Item & $\mathrm{I}$ & 2 & 3 \\
\hline $\mathrm{I}$ & .63 & & \\
2 & .50 & & \\
3 & .81 & .78 & \\
4 & & .90 & .66 \\
5 & & .34 & .36 \\
6 & & & .74 \\
7 & & & .76 \\
8 & & & \\
9 & & & \\
\hline
\end{tabular}

$\mathrm{I}=$ Behaviour awareness and volition; 2 = task motivation; 3 = constructive cognition.

The results of the incremental fit measures indicate that, when compared to a baseline model, the first-order measurement model unlike the single-factor measurement model achieved NFI, NNFI, CFI, IFI, and RFI >.90, which represents good fit (Hair, Anderson, Black, Babin, \& Black, 2010; Kelloway, 1998). These incremental and relative indices therefore show good model fit.

The completely standardised factor loadings are shown in Table 4. The values shown in the completely standardised solution loading matrix indicate the average change expressed in standard deviations ( $S D \mathrm{~s})$ in the item associated with $1 S D$ change in the latent variable (Diamantopoulos \& Siguaw, 2000). The factor loadings of the items are generally significant $(>.30)$.

\section{Discriminant validity}

A test for discriminant validity was conducted using the method put forward by Farrell (2010). This method entails ascertaining the discriminant validity among two or more factors by comparing the average variance extracted (AVE) of each construct with the shared variance between constructs. The AVE indicates the average proportion of variance in the indicator variables that is accounted for by the latent variable reflected by the manifest variables (Diamantopoulos \& Siguaw, 2000). This is achieved through the use 
of measurement error terms from the CFA output. If the AVE for each construct is greater than its shared variance with any other construct, discriminant validity is supported. In this case, none of the shared variance estimates is greater than the AVE estimates for each of the constructs; therefore, discriminant validity is supported (see Table 2).

\section{Power assessment}

A Rweb (1.03) translation of the SAS syntax provided by Preacher and Coffman (2006) was used to derive the power estimates for the tests of exact and close fit. In this study, a significance level ( $\alpha$ ) of .05, a sample size of 400, and 24 degrees of freedom were the inputs for the power calculations. A power value of 0.832062 was obtained for the test of exact fit, while SAS syntax returned a value of 0.8275498 for the test of close fit. In this case, the null hypothesis of exact fit was rejected. The high power value for the test of close fit implies that under the conditions that characterised this specific study, approximately $0.8275498 \%$ of incorrect models would be rejected. This increases confidence in the model.

\section{Discussion}

The objective of this study was to evaluate the portability of the ASLQ (Houghton et al., 2012) by testing the reliability and construct validity of the ASLQ on a South African sample.

The reliability coefficients for the three subscales indicate moderate reliability with all the coefficients slightly below the .70 threshold (Nunnally \& Bernstein, 1994). This is in stark contrast to the reliability coefficients obtained for the full version of the instrument, that is, the RSLQ (Mahembe et al., 2013; Nel \& Van Zyl, 2015). The reliability coefficients of the RSLQ ranged from .74 to .90 (Mahembe et al., 2013). Treating the ASLQ as a unidimensional scale also resulted in an acceptable reliability coefficient although the factorial validity via EFA indicated the presence of three factors. Due to the limited number of the ASLQ items per subscale, efforts to improve the reliability coefficients are not possible. In terms of construct validity, the first-order model showed reasonable model fit to the data. However, the single-factor model CFA showed poor model fit despite its better reliability coefficient.

The individual factor loadings were also assessed to further determine the construct validity. The completely standardised factor loadings estimates are generally above .50 with the exception of two items (When I have successfully completed a task, I often reward myself with something I like; Sometimes I talk to myself [out loud or in my head] to work through difficult situations) (Hair et al., 2010).

Based on the outcomes of this study on a South African sample of undergraduate students, it can be concluded that the ASLQ shows moderate reliability coefficients and reasonable construct validity. This outcome is not consistent with some previous findings reported for the full version (RSLQ) in countries such as Turkey (Dogan \& Sahin, 2008), Germany (Andressen \& Konradt, 2007), China (Ho \& Nesbit, 2009), Portugal (Curral \& MarquesQuinteiro, 2009), and South Africa (Mahembe et al., 2013; Nel \& Van Zyl, 2015). More 
studies are therefore needed to confirm the suitability of the ASLQ factor structure on a South African student sample and its compliance with the requirements of the Amended Employment Equity Act of South Africa (Republic of South Africa, 1998, 2014) in terms of its reliability and validity.

This study was not without some limitations. Since this study was carried out as a quantitative survey, it therefore suffers from all the potential problems of this kind of research method, that is, social desirability, response set, and mono-method bias. Consequently, it is proposed that this study be replicated to include a more heterogeneous sample comprising employees from both the public and private sectors to ascertain whether similar results would be obtained. This study highlighted some weaknesses in the subscales such as the low reliability coefficients especially for the constructive cognition subscale. It is therefore suggested that future studies further develop the subscales since these subscales consist of only three items per scale possibly to four items each.

Although the study was less skewed in terms of gender, the sample may not be representative of the South African sample given that the non-probability sampling technique was used. This technique affects the generalisability of the findings. Future studies should replicate the study using bigger sample sizes.

More conclusive research on the psychometric properties of the ASLQ is required. Future studies should also determine the measurement equivalence and measurement invariance of the ASLQ across different South African cultural groups. Future studies should also investigate the discriminant validity of the latent dimensions.

\section{Conclusion}

The psychometric evaluation of the ASLQ in this study indicates reasonable construct validity and moderate reliability coefficients. The practical contribution of the study is in the advancement of the body of knowledge on the psychometric properties of the ASLQ on a student sample from the Western Cape Province of South Africa. The study contributes to the advancement of the use of valid and reliable instruments as required by the Employment Equity Act (No. 55 of 1998) and the Amended Employment Equity Act of South Africa (Republic of South Africa, 1998, 2014) which requires all test developers and users to consider the psychometric properties of measures before they can be used in South Africa. The use of the ASLQ is important as it offers a shorter and more convenient alternative for the measurement of self-leadership using nine items compared to the original 35-item questionnaire.

\section{Funding}

The author(s) received no financial support for the research, authorship, and/or publication of this article. 


\section{Note}

According to the Employment Equity Act, the race categories in South Africa can be described as White (European descent), African (African descent, previously in apartheid described as Black), Coloured (mixed race descent), and Indian (of India descent). 


\section{References}

Alves, J. C., Lovelace, K. L., Manz, C. C., Matsypura, D., Toyasaki, F., \& Ke, K. G. (2006). Cross-cultural perspective of self-leadership. Journal of Managerial Psychology, 21, $338-359$.

Anderson, J. S., \& Prussia, G. E. (1997). The self-leadership questionnaire: Preliminary assessment of con- struct validity. Journal of Leadership Studies, 4, 119-143.

Andressen, P., \& Konradt, U. (2007). Measuring self-leadership: Psychometric test of the German version of the revised self-leadership questionnaire. Zeitschrift fur Personalpsychologie, 6, 117-128.

Bandura, A. (1977). Self-efficacy: Toward a unifying theory of behavioral change. Psychological Review, 84, 191-215.

Bandura, A. (1986). Social foundations of thought and action: A social cognitive theory. Upper Saddle River, NJ: Prentice Hall.

Barling, J., \& Beattie, R. (1983). Self-efficacy beliefs and sales performance. Journal of Organizational Behavior Management, 5, 4-51.

Bligh, M. C., Pearce, C. L., \& Kohles, J. C. (2006). The importance of self- and shared leadership in team based knowledge work. Journal of Managerial Psychology, 21, 296-318.

Burger, R. (2012). Elaboration and empirical evaluation of the De Goede learning potential structural model (Unpublished master's thesis). Stellenbosch University, Stellenbosch, South Africa.

Carver, C. S., \& Scheier, M. F. (1981). Attention and self-regulation: A control theory approach to human behaviour. New York: Springer.

Cautela, J. R. (1969). Behaviour therapy and self-control: Techniques and applications. In C. M. Franks (Ed.), Behavior therapy: Appraisal and status (pp. 323-340). New York: McGraw-Hill.

Cox, J. F. (1993). The effects of super-leadership training on leader behaviour, subordinate self-leadership behaviour, and subordinate citizenship (Unpublished doctoral dissertation). University of Maryland, College Park, MD, USA.

Cunnington, B. (1985). The process of educating and developing managers for the year 2000. Journal of Management Development, 4, 566-579.

Curral, L., \& Marques-Quinteiro, P. (2009). Self-leadership and work role innovation: Testing a mediation model with goal orientation and work motivation. Revista de Psicologıa del Trabajo y de las Organizaciones, 25, 163-174.

De Goede, J., \& Theron, C. C. (2010). An investigation into the internal structure of the learning potential construct as measured by the APIL-B test battery. Management Dynamics, 19, 30-55.

Deci, E., \& Ryan, R. (1985). The support of autonomy and control of behaviour. Journal of Personality and Social Psychology, 53, 1024-1037.

Diamantopoulos, A., \& Siguaw, J. A. (2000). Introducing LISREL. London, UK: SAGE.

DiLiello, T. C., \& Houghton, J. D. (2006). Maximizing organizational leadership capacity for the future: Toward a model of self-leadership, innovation and creativity. Journal of Managerial Psychology, 21, 319-337. 
Dogan, S., \& Sahin, F. (2008). A study of reliability, validity and adaptation of revised selfleadership questionnaire-RSLQ to Turkish context. Journal of Economics and Administrative Sciences, 26, 139-164.

Du Toit, M., \& Du Toit, S. H. C. (2001). Interactive LISREL: User's guide. Lincolnwood, IL: Scientific Software International.

Esterhuyse, W. (2008). Monduitspoel: Inploffing. Die Burger. Saturday 2 August.

Farrell, A. M. (2010). Insufficient discriminant validity: A comment on Bove, Pervan, Beatty and Shu. Business Research, 63, 324-327.

Gil, F., Rico, R., Alcover, C. M., \& Barrasa, A. (2005). Change-oriented leadership, satisfaction and performance in work groups: Effects of team climate and group potency. Journal of Managerial Psychology, 20, 312-328.

Hair, J., Anderson, R., Black, B., Babin, B., \& Black, W. C. (2010). Multivariate data analysis. Upper Saddle River, NJ: Prentice Hall.

Ho, J., \& Nesbit, P. L. (2009). A refinement and extension of the self-leadership scale for the Chinese context. Journal of Managerial Psychology, 24, 450-476.

Houghton, J. D., Dawley, D., \& DiLiello, T. C. (2012). The abbreviated self-leadership questionnaire (ASLQ): A more concise measure of self-leadership. International Journal of Leadership Studies, 7, 216-232.

Houghton, J. D., \& Neck, C. P. (2002). The revised self-leadership questionnaire: Testing a hierarchical factor structure for self-leadership. Journal of Managerial Psychology, 17, 672-691.

IBM Corporation (2015). IBM SPSS statistics for windows, version 23.o. Armonk, NY: Author.

Jöreskog, K. G., \& Sörbom, D. (1996). LISREL 8: User's reference guide. Chicago: Scientific Software International.

Jöreskog, K. G., \& Sörbom, D. (2006). Interactive LISREL 8.8o. Chicago: Scientific Software International. Kanfer, F. H. (1970). Self-regulation: Research, issues, and speculation. In C. Neuringer \& J. L. Michael (Eds.), Behaviour modification in clinical psychology (pp. 178-220). New York: Appleton-Century-Crofts.

Kelloway, E. K. (1998). Using LISREL for structural equation modelling: A researcher's guide. Thousand Oaks, CA: SAGE.

Mahembe, B. (2014). The development and empirical evaluation of an extended learning potential structural model (Unpublished doctoral thesis). Stellenbosch University, Stellenbosch, South Africa.

Mahembe, B., Engelbrecht, A. S., \& De Kock, F. S. (2013). A confirmatory factor analytic study of a self-leadership measure in South Africa. SA Journal of Human Resource Management, 11, 1-10.

Manz, C. C. (1986). Self-leadership: Toward an expanded theory of self-influence processes in organizations. Academy of Management Review, 11, 585-600.

Manz, C. C. (1991). Leading employees to be self-managing and beyond: Toward the establishment of self-leadership in organisations, Journal of Management Systems, $3,15-24$.

Manz, C. C. (1993a). The art of positive psyching: Skills for establishing constructive thinking patterns. King of Prussia, PA: Organization Design and Development. 
Manz, C. C. (1993b). Becoming a self-manager: Skills for addressing difficult, unattractive, but necessary tasks. King of Prussia, PA: Organization Design and Development.

Manz, C. C. (1993c). Redesigning the way you do your job: Skills for building natural motivation into your work. King of Prussia, PA: Organization Design and Development.

Manz, C. C., \& Neck, C. P. (2004). Mastering self-leadership: Empowering yourself for personal excellence (3rd ed.). Upper Saddle River, NJ: Prentice Hall.

Markham, S. E., \& Markham, I. S. (1998). Self-management and self-leadership reexamined: A levels of analysis perspective. In F. Dansereau \& F. J. Yammarino (Eds.), Leadership: The multiple-level approaches, classical and new wave (pp. 193-210). Stamford, CT: JAI Press.

Neck, C. P., \& Houghton, J. D. (2006). Two decades of self-leadership theory and research: Past developments, present trends, and future possibilities. Journal of Managerial Psychology, 21, 270-295.

Neck, C. P., \& Manz, C. C. (1996). Thought self-leadership: The impact of mental strategies training on employee behaviour, cognition, and emotion. Journal of Organizational Behavior, 17, 445-467.

Neck, C. P., \& Manz, C. C. (2010). Mastering self-leadership: Empowering yourself for personal excellence (5th ed.). Upper Saddle River, NJ: Prentice Hall.

Neck, C. P., Stewart, G., \& Manz, C. C. (1995). Thought self-leadership as a framework for enhancing the performance of performance appraisers. Journal of Applied Behavioral Science, 31, 278-302.

Nel, P., \& Van Zyl, E. (2015). Assessing the psychometric properties of the revised and abbreviated self-leadership questionnaires. SA Journal of Human Resource Management/SA Tydskrif vir Menslikehulpbronbestuur, 13, 1-8.

Neubert, M. J., \& Wu, J. C. (2006). A cross-cultural validation of the Houghton and Neck self-leadership measure. Journal of Managerial Psychology, 21, 360-373.

Norris, S. E. (2008). An examination of self-leadership. Emerging Leadership Journeys, 1, 43-61. Nunnally, J. C., \& Bernstein, I. H. (1994). Psychometric theory (3rd ed.). New York: McGraw-Hill.

Preacher, K. J., \& Coffman, D. L. (2006). Computing power and minimum sample size for RMSEA [Computer software]. Available from http://quantpsy.org/

Republic of South Africa. (1998, October 19). Employment Equity Act. Government Gazette, No. 19370. Republic of South Africa. (2014). Amended Employment Equity Act. Government Gazette, No. 19370. Ross, S. (2014). A conceptual model for understanding the process of self-leadership development and action-steps to promote personal leadership development. Journal of Management Development, 33, 299323. Rubin, D. B. (1987). Multiple imputation for nonresponse in surveys. New York: John Wiley \& Sons.

Ryan, R. M., \& Deci, E. L. (2000). Self-determination theory and the facilitation of intrinsic motivation, social development, and well-being. American Psychologist, 55, $68-78$. 
Stajkovic, A. D., \& Luthans, F. (1998). Self-efficacy and work related performance: A meta-analysis. Psychological Bulletin, 124, 240-261.

Stewart, G. L., Courtright, S. H., \& Manz, C. C. (2011). Self-leadership: A multilevel review. Journal of Management, 37, 185-222.

Tabachnick, B. G., \& Fidell, L. S. (2001). Using multivariate statistics (4th ed.). Needham Heights, MA: Allyn \& Bacon.

Thoresen, C. E., \& Mahoney, M. J. (1974). Behavioral self-control. New York: Holt McDougal. Tichy, N., \& Sherman, S. (1993). Control your destiny or someone else will. New York: Wiley.

Van Heerden, S., \& Theron, C. (2014). The elaboration and empirical evaluation of the De Goede learning potential structural model. South African Journal of Business Management, 45, 1-30.

Van Zyl, E. (2008). The relation between stress and self-leadership characteristics among a group of first-line supervisors working in a state organisation. Tydskrif vir Geesteswetenskappe, 48, 454-466. 